\title{
CONSTRUINDO CONHECIMENTOS EM SUSTENTABILIDADE SOCIOAMBIENTAL NO PONTAL DO PARANAPANEMA, SP.
}

\section{Maria das Graças de Souza ${ }^{1}$ \\ Mirian M. Ikeda² \\ Williana Souza Leite Marin ${ }^{3}$}

RESUMO: Este trabalho teve como objetivos identificar as contribuições que o projeto "Construção Coletiva de Conhecimentos para a Sustentabilidade Socioambiental do Pontal do Paranapanema", propiciou para o enriquecimento de saberes e práticas na área socioambiental junto a diferentes atores sociais na região do Pontal do Paranapanema, extremo oeste do Estado de São Paulo. Utilizou-se no desenvolvimento deste estudo a adoção de processos contemplando avaliações qualitativas e quantitativas nos quais os dados foram obtidos por diversos instrumentos de coleta, incluindo questionários, observações diretas, registros de solicitações e depoimentos. $O$ estudo foi pautado nos referenciais teóricos da abordagem participativa e da pesquisa-ação, adotados no desenvolvimento das atividades sócio-educativas do projeto e realizado junto a 04 municípios inseridos na Bacia hidrográfica do Pontal do Paranapanema. Os públicos alvos abordados neste estudo incluíram estudantes, professores, gestores de ensino e comunidade em geral. Os resultados indicam que o projeto contribuiu para os processos de construção coletivas de saberes e práticas socioambientais junto a alunos, professores e membros da comunidade local e constitui-se num modelo de estratégia educacional facilitadora para a construção de espaços e oportunidades de aprendizagens coletivas na área socioambiental. Os resultados indicam também que as estratégias sócio-educativas adotadas pelo projeto junto aos seus públicos alvos, contribuíram para ampliar a prática da temática socioambiental dentro e fora das salas de aulas e maior integração entre sociedade e tomadores de decisões locais.

${ }_{1}^{1}$ IPÊ-Instituto de Pesquisas Ecológicas, gracinha@ipe.org.br

${ }^{2}$ IPÊ-Instituto de Pesquisas Ecológicas, ikeda@ipe.org.br

${ }^{3}$ ws marin@ipe.org.br 
PALAVRAS-CHAVES: Educação ambiental. Sustentabilidade socioambiental. Aprendizagens coletivas.

\section{INTRODUÇÃO}

O Pontal do Paranapanema faz parte da Região Administrativa de Presidente Prudente que é constituída por 53 municípios que integram o extremo oeste do Estado de São Paulo. Localizado entre a confluência dos Rios Paraná e Paranapanema, o Pontal está incluído dentro dos limites do decreto 750 que define legalmente a existência e os domínios da Mata Atlântica, (Ditt, 2008). A Mata Atlântica de Interior é caracterizada pela rica biodiversidade, com a presença de espécies raras e endêmicas constituindo o 'banco genético' de um dos ecossistemas mais ameaçados do país, (Câmara, 1993).

Apesar de ter sobrado pouca cobertura natural original, os remanescentes de Mata Atlântica do Interior encontrados na região são de inegável riqueza biológica salvaguardando vários corpos d'água de suma importância para toda região do Pontal. Estes têm sido a fonte de alternativas de desenvolvimento sustentável que vêm beneficiando tanto a população local, quanto as condições ambientais da paisagem do Pontal.

Os principais problemas socioambientais do Pontal do Paranapanema estão correlacionados a dinâmica de ocupação da região com intensos desmatamentos, aceleração do processo erosivo em áreas urbanas e rurais, assoreamento e desperenização de cursos d'água, lançamento de esgotos urbanos não tratados, deposição irregular de lixo em nascentes e fundos de vales, exploração sem controle da água subterrânea, conflitos fundiários e o aumento crescente da demanda de água (Leal, 2000).

É neste cenário que o projeto "Construção Coletiva de Conhecimentos para a Sustentabilidade Socioambiental do Pontal do Paranapanema", propôs atuar para provocar construções coletivas de conhecimentos que gerassem contribuições para a compreensão da situação de degradação ambiental e mobilização para busca de alternativas para o desenvolvimento sustentável do Pontal do Paranapanema. A capacitação para as questões 
socioambientais em educação ambiental é ainda um campo deficiente no Brasil, apesar da riqueza biológica encontrada no território nacional.

Pouca atenção tem sido dada à área de formação de indivíduos que estejam aptos a valorizar a natureza, e esta falha certamente contribui para posturas de desrespeito e agressão ao meio ambiente no País. O Brasil retém 30\% das florestas tropicais do mundo, sendo seu patrimônio natural considerado mega diverso. Este valor, no entanto, não é largamente reconhecido. A educação poderia ajudar a voltar às atenções de tomadores de decisão e da sociedade para o valor da natureza, priorizando-os nos rumos a serem trilhados.

Sem infra-estrutura adequada e sem pessoal especializado, a proteção das riquezas naturais do País depende de uma mudança de valores e atitudes em relação à proteção ambiental e ao uso sustentável dos recursos naturais. Esta deveria ser a base de uma nova capacitação e educação oferecida a todo o cidadão brasileiro. Com uma educação efetiva para os diferentes níveis de ensino que incluísse a conservação de recursos hídricos, educação ambiental, aliada à teoria e à prática da biologia da conservação, muitas das agressões observadas atualmente, certamente teriam mais chances de serem evitadas.

A Educação Ambiental é uma ferramenta importante para comunicar sobre questões ambientais locais, envolver pessoas em ações que visam bem coletivos, incentivar pessoas a mudanças de práticas, atitudes e comportamentos e também a respeitar o ambiente em que vivemos, bem como também sua diversidade cultural e biológica.

A educação ambiental é um instrumento que permite facilitar a percepção e o envolvimento do ser humano com as questões ambientais de seu entorno, compreendendo melhor as relações existentes entre as ações que a sociedade toma considerando os usos e apropriações dos recursos hídricos e naturais e as conseqüências resultantes. Neste contexto, as ações de educação planejadas no desenvolvimento do projeto em análise buscaram essencialmente, integrar os interesses dos diversos atores sociais, mostrando que a qualidade de um pode afetar diretamente a condição do outro e buscou promover ações de capacitação ambiental, de comunicação, de sensibilização e de mobilização 
comunitária, além da articulação política institucional capazes de gerar benefícios socioambientais diversificados.

\section{DESENVOLVIMENTO}

O projeto "Construção Coletiva de Conhecimentos para a Sustentabilidade Socioambiental do Pontal do Paranapanema" foi desenvolvido no período de julho de 2012 a julho de 2013 tendo como cidade alvo de suas ações sócio-educativas, o município de Teodoro Sampaio-SP, Pontal do Paranapanema.

A metodologia norteadora das estratégias adotadas para o alcance dos objetivos educacionais, foi a denominada como participativa (Padua, 2003), considerada uma das mais adequada às atividades nas áreas sociais. Esta abordagem metodológica é fundamentada no que se recomenda a linha básica da pesquisa-ação, descrita por Barbier (1996), e Thiollent (1994) e onde os próprios atores envolvidos nas intervenções educativas propiciadas pelo projeto, constroem suas realidades socioambientais e transformam suas posturas e condutas, seus modos de se relacionarem entre si, com ou demais atores e com o meio em que vivem.

Para mensurar o impacto do projeto junto aos públicos alvos definidos originalmente, foram utilizados processos de avaliação qualitativa e quantitativa, sendo os dados analisado, obtidos por instrumentos de coletas que incluíram pré e pós-questionários compostos por questões abertas e fechadas, avaliação diária, registros de observações diretas e depoimentos registrados. Responderam aos questionários aplicados, alunos, professores e membros da comunidade participante das atividades de acordo com o que recomenda, NOGUEIRA, 1964.

O cardápio de ações sócio-educativas desenvolvido pelo projeto, foi planejado de forma participativa junto a atores sociais locais, considerando demandas do campo socioambiental, identificadas como prioritárias em documentos produzidos por diversas instituições que atuam no dia-a-dia junto as comunidades constituintes do público alvo do projeto. Registros onde estas demandas são identificadas incluem, por exemplo, o Plano de Bacia para a área de abrangência do Comitê da Bacia Hidrográfica do Pontal do Paranapanema, conforme dados do Relatório de Situação dos Recursos Hídricos do Pontal 
do Paranapanema (CBH-PP/2009), Diretivas de Educação Ambiental do Programa Município Verde Azul da Secretaria Estadual de Meio Ambiente, Plano Decenal Municipal de Educação do Município de Teodoro Sampaio, Currículo Estadual da Secretaria de Estado da Educação e Fóruns Participativos: "Eco-Negociação: Um Pontal Bom Para Todos" desenvolvidos no período de 2000 a 2005.

Os conteúdos sócio-educativos integrantes do cardápio de ações didáticas propiciadas pelo projeto junto aos públicos abordados, incluíram a realização de Palestras informativas, que promoveram aquisição de conhecimentos; Espaços dirigidos de aprendizagens coletivas (tendas itinerantes montadas em espaços públicos comunitários, com atividades de educação ambiental; Realização de encontros participativos de informação e articulação institucional, direcionados a professores e jovens; Oficinas de capacitação em produção de mudas e conservação de recursos hídricos, dirigidas a estudantes, professores e membros da comunidade local e um Curso de capacitação em educação ambiental para professores do ensino fundamental e médio do município de Teodoro Sampaio. Todas as estratégias educativas adotadas abordavam temáticas em conservação e sustentabilidades socioambiental dos bens naturais da região.

Tais estratégias didáticas foram adotadas como instrumentos facilitadores de provocação nos públicos abordados, uma otimização das oportunidades para aquisição e troca de conhecimentos, competências e disseminação de informações na ampliação de consciência coletiva e a sensibilização, para o envolvimento e a participação em ações de em prol a conservação dos recursos hídricos, florestais e da biodiversidade na região do Pontal do Paranapanema.

O projeto "Construção Coletiva de Conhecimentos para a Sustentabilidade Socioambiental do Pontal do Paranapanema", pela natureza diversificada de suas propostas pedagógicas possibilitou a comunidade local uma rica oportunidade para 0 desenvolvimento de aprendizagens coletivas, ao chegar ao seu final com a realização de 20 palestras proferidas abordando temáticas socioambientais diversas características da região do Pontal do Paranapanema; 15 Espaços Itinerantes de educação ambiental realizados em diferentes ambientes comunitários (escolas, praças, centros comunitários e clubes de serviços); 06 oficinas de arte-educação e capacitação socioambiental realizadas; 01 Encontro de Professores e Diretores para apresentação do projeto e objetivos 
educacionais na comunidade local; 01 Encontro participativo de jovens e sustentabilidade socioambiental; 01 Curso de educação ambiental para professores e ou coordenadores do Ensino Fundamental do município de Teodoro Sampaio; 2000 mudas de árvores nativas distribuídas a estudantes, jovens, mulheres e comunidade em geral; 500 folhas de atividades diversas (caça palavras, cruzadinhas, desenhos para pintar sobre biodiversidade, curiosidades ecológicas entre outras atividades educativas) sobre conservação e sustentabilidade na região do Pontal, distribuídas a alunos, professores e comunidade em geral; 01 folder temático árvore e biodiversidade, distribuído na comunidade escolar; 01 mutirão de lixo eletrônico realizado envolvendo 03 escolas de Ensino Fundamental e Médio, coletando aproximadamente 01 tonelada de equipamentos eletro-eletônicos encaminhados com destinação adequada; 01 semana comemorativa realizada em parceria com instituições públicas e privadas, em prol ao dia mundial do meio ambiente, integrando comunidade estudantil e comunidade local.

Com a realização das estratégias educativas realizadas, mais de 5.000 pessoas foram abordadas pelas ações do projeto na região do Pontal do Paranapanema.

\section{CONCLUSÃO}

Os resultados educacionais, sócios e ambientais alcançados com 0 desenvolvimento do projeto "Construção Coletiva de Conhecimentos para a Sustentabilidade Socioambiental do Pontal do Paranapanema", demonstram o impacto que o referido projeto proporcionou para o campo da educação para a conservação e a sustentabilidade socioambiental da região do Pontal do Paranapanema. Resultados indicam que o projeto possibilitou a) acesso à informação atualizada, a cerca das principais ameaças à biodiversidade, às florestas e aos recursos hídricos e a sustentabilidade destes bens naturais em longo prazo para a garantia dos serviços ecossistêmicos oferecidos gratuitamente as pessoas da região; b) beneficiou diretamente professores, mulheres, estudantes e jovens com capacitação para lidar com temáticas socioambientais características da realidades ambiental local; c) incluiu mulheres assentadas em atividades de capacitação ambiental; d) enriqueceu práticas educativas sustentáveis desenvolvidas nas escolas rurais, urbanas e rurais de assentamentos de reforma agrária; e) abordou 
diretamente de forma integrada e participativa escolas estaduais, municipais, associação e creches do município (Escolas Estaduais: EE Salvador M. Munhoz, EE Lidia Sanaye Oya, EE Shizuo Nishikawa e Escolas Municipais: EMEF José Amador, EMEF Pedro Caminoto, EMEIF Pref. Paulo Pires, EM Marabá Paulista, creche CEI Monsenhor Jesus Pereira dos Anjos Núcleo I e Núcleo II e a Associação Pró Menor-Projeto Guarda Mirim Ambiental); e f) envolveu participativamente em suas práticas sócio-educativas empreendimentos sustentáveis comunitários bem sucedidos, caracterizados pelos viveiros agroflorestais comunitários; g) promoveu maior divulgação dos bens naturais abordados na comunidade local abordada e h) contribuiu para o aumento no número de árvores nativas plantadas no município.

Os resultados indicam ainda que, a ocorrência de diversas ações sócio-educativas desencadeadas na comunidade pelos públicos participantes do projeto após a realização do mesmo, constitui indicadores de sucesso para o alcance dos objetivos do projeto na construção coletiva de conhecimentos para a sustentabilidade socioambiental da região do Pontal do Paranapanema.

Os indicadores adotados para mensurar tal afirmativa incluem: a) a solicitação de material didático pelas escolas para replicarem as atividades que o projeto proporcionou a determinada sala de aula, para poderem replicarem em outras salas, configurando uma ampliação do escopo de ação do projeto; b) o desenvolvimento de trabalhos escolares com as temáticas ambientais abordadas pelas ações do projeto envolvendo alunos e professores (a escola EE SMM fez vários murais contendo redações produzidas pelos alunos e desenhos com os motivos da biodiversidade retratada pela ação do projeto, na ocasião de palestras e oficinas, já a escola EMEIF JA, utilizou dos materiais didáticos, uma cartilha ecológica sobre a fauna local, disponibilizados na ocasião do curso de capacitação para professores para trabalharem com os alunos nos momentos de leitura em classe, abordando um dos animais da fauna local, a anta); c) Solicitação de apoio as atividade educativas na escolas contempladas pelo projeto (palestra, jogos ecológicos, vídeos, imagens de animais da biodiversidade local para subsidiar ações educativas socioambientais dentro da sala de aula); d) Solicitação de mudas de árvores para ações de restauração florestal em assentamento e embelezamento de espaços escolares; e) Inserção do projeto em agenda cultural do município (convite para o desfile de aniversário 
do município); f) Inserção do projeto em agenda educacional da Escola Técnica ETEC Profa. Nair Lucas do Centro Paula Souza na Semana Paulo Freire da referida escola; g) Voluntariado de 03 alunos do Ensino Fundamental, Médio e Universitário nas ações do projeto desenvolvidas com as comunidades locais; h) a adesão de $100 \%$ das escolas municipais no curso de educação ambiental para professores.

O "projeto Construção Coletiva de Conhecimentos para a Sustentabilidade Socioambiental do Pontal do Paranapanema" foi realizado com o apoio do Programa Oi Novo Brasis - OI FUTURO.

\section{REFERÊNCIAS}

BARBIER, René. (1996). A Pesquisa-ação. Paris: Ed. Econômica, 1996. Tradução Professora Lucie Didio, UFRS, 1996 (Documento mimeografado).

CÂMARA, Ibsen de Gusmão. Plano de ação para a Mata Atlântica. São Paulo: Fundação SOS Mata Atlântica. 1993.

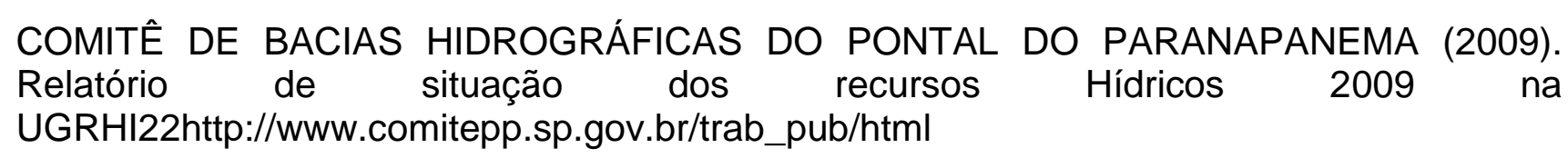

DITT, Eduardo Humberto (2008): Fragmentando e desfragmentando paisagens: lições da Mata Atlântica e da Floresta Amazônica. In: BENSUSAN, Nurit; ARMSTRONG, Gordon. O Manejo da Paisagem e a Paisagem do Manejo. Brasília, DF.

IPÊ, Instituto de Pesquisas Ecológicas (2005). Relatório Técnico do Fórum Participativo: Eco-negociação: Um Pontal Bom Para Todos".

LEAL. A. C.(2000). Gestão das Águas no Pontal do Paranapanema. São Paulo, Campinas, 2000. Tese (doutorado em Geociências) - Instituto de Geociências, Universidade Estadual de Campinas. (www.prudente.unesp.br/hp/cezar/)

NOGUEIRA, O. (1964). Pesquisa social: introdução às suas técnicas. São Paulo: Companhia Editora Nacional, 209p.

PADUA, S. M.; TABANEZ, M. F.; SOUZA, M. G. (2003). A Abordagem Participativa na educação para a conservação da natureza. In: CULLEN JUNIOR, L.; RUDRAN, R.; VALLADARES-PADUA, C. Métodos de Estudo em Biologia da Conservação \& Manejo da Vida Silvestre. Curitiba: UFPR; Fundação O Boticário de Proteção à Natureza. 
THIOLLENT, M. Metodologia da Pesquisa-Ação. São Paulo: Cortez Editora. 1994. 